\title{
Comparative Analysis of Antimicrobial Activity of Herbal Extracts against Pathogenic Microbes
}

\author{
Pooja Agrawal, DivyaKotagiri andViswanatha Chaitanya Kolluru* \\ Department of Biotechnology, GITAM University, India
}

Submission: April 20, 2018; Published: July 05, 2018

*Corresponding author: Viswanatha Chaitanya Kolluru, Department of Biotechnology, GITAM Institute of Technology, GITAM University, Visakhapatnam, 530045, Andhra Pradesh, India, Email: viswanatha.chaitanya@gmail.com

\begin{abstract}
Antimicrobial activities of Spinacia oleracealeaf, Zingiberofficinalerhizome, Coriandrum sativum leaf, Allium sativum clove, Aloe vera gel and leaf was carried out against the multi-drug resistant strains using the minimum inhibitory concentration method. The direct TLC bioautography method is performed to identify the bioactive compounds present in the extracts exhibiting the antimicrobial property.All the plant extracts effectively inhibited the growth of pathogenic strains used in the study at a concentration of 250 to $31.25 \mathrm{mg} / \mathrm{ml}$. These results provide evidence that the tested plant extracts possess antimicrobial properties which can be tested further in the development of novel antimicrobial agents.

Keywords: Antimicrobial activity; TLC bioautography method; Herbal extracts; multi-drug resistant strains; Mcfarland

Abbreviations: MIC: Minimum Inhibitory Concentration; DMSO: Dimethyl Sulfoxide; TLC: Thin Layer Chromatography; NCIM:National Collection of Industrial Microorganisms; CFU: Colony Forming Units
\end{abstract}

\section{Introduction}

The emergence of multi-drug resistant microorganisms with decreased susceptibility to antibiotics due to improper usage of broad spectrum drugs is increasing day by day globally. In developing countries, the increase in the rate of mortality and morbidity is due to the infectious diseases [1,2]. Synthetic drugs which are used to treat infectious diseases are expensive and often cause side effects. Hence, there is a need to develop novel drugs to control the spread of pathogenic microbial strains. Plants with medicinal value are of interest as they are the richest source of secondary metabolites with therapeutic properties considered to be safe and effective compared to synthetic drugs [3]. The different types of plant material like leaves, root, stem, flowers, fruits and vegetables are potential sources of antimicrobial compounds due to the presence of bioactive compounds. Medicinal plants contain large number of secondary phytomedicines like phenols, flavonoids, alkaloids, saponins, tannins, steroids etc. possesses synergistic effects used for remedial purposes [4]. These secondary bioactive compounds have different structures with different mode of action used to control microbial growth and survival. Therefore, many dreadful diseases can be cured with the use of plant preparations [5]. The importance of natural products obtained from plants remains unchanged even after the developments in the field of synthetic organic chemistry and pharmacology. They have been used widely as traditional medicine and particularly when synthetic drugs are inaccessible and unaffordable [6]. A large number of plant species were screened for their antimicro bial properties by many researchers till now. Since ancient times, herbs and spices have been used as flavoring agents, food additives and as preservatives. They are effective in eradicating the microbial population, used widely in food industries generally considered as safe. The antimicrobial activity varies depending upon the type of food, type of spice, microorganism, essential oils and type of extracts used [7]. The study of bioactive compounds and the development of plant based antimicrobial drugs have gained importance in current research due to increase in demand for safe and effective drugs.

The present study mainly focused on Aloeveragel,Aloe veraleaf,Spinacia oleracea leaf,Zingiberofficinalerhizome, Coriandrum sativum leaf and on an Allium sativumclove to evaluate their antimicrobial properties which could provide valuable information in order to use them as therapeutic tools for control of microbial growth. The extracts were prepared using solvents of different polarities and the antimicrobial activity was tested against multi-drug resistant strains of Escherichia coli, Candida albicans, Enterococcus faecalis, Staphylococcus aureus, Streptococcus mutans, Klebsiella pneumonia andMycobacterium smegmatis using MIC method.The direct TLC bioautography method is used as a tool to detect and isolate the antimicrobial compounds from plant extracts directly even in small amounts and is considered to be a good method compared to agar dilution methods.Aloe vera is a succulent plant well known for its medicinal properties belongs to the family of "Aloaceae". It is a stemless plant grows up to a 
height of $60-100 \mathrm{~cm}$ and the leaves are thick and fleshy [8]. Polysaccharides, monosaccharides, chromones, anthraquinones, organic compounds, inorganic compounds, vitamins and enzymes are some of the active compounds present in Aloe vera were responsible for antibacterial, antifungal, antioxidant, wound healing and anti-diabetic properties $[9,10]$.

The antimicrobial effects of Aloe vera have been attributed to the plant's natural anthraquinones capable of inhibiting the strains of Mycobacteriumtuberculosis and Bacillus subtilis. The thick, colorless mucilaginous gel material present within the leaves of Aloe vera is considered to be effective in curing gastrointestinal diseases [11], burns and wounds [12]. It is also used to boost up the immune system in humans [13] and the products obtained from Aloe vera are used widely in cosmetic, food and pharmaceutical industries [14]. Coriandrum sativum also known as dhania is an annual herb belongs to the family of "Apiaceae". It grows up to a height of $50 \mathrm{~cm}$. The leaves are variable in shape, broadly lobed at the base of the plant. It is used to treat diarrhea, vomiting, rheumatism, cough, dysentery, joint pains and indigestion [15]. It possesses antidiabetic, anti-inflammatory, lipolytic, antihypertensive, nerve relaxing and antiseptic properties. The coriander extracts possess free radical scavenging, antioxidant, antimutagenic, anticancerous and antibacterial properties [16]. Allium sativumcommonlycalled as garlic is a bulbous plantbelongs to the family of "Amaryllidaceae". It has good anti-bacterial and anti-fungal properties. Garlic is used to prevent high blood pressure, high cholesterol and heart diseases, provides protection against cancer [17].Spinacia oleracea commonly known as Palak/ spinach used widely in India is an edible flowering plant belongs to the family of "Chenopodiaceae". It is used to treat leprosy, asthma, urinary diseases, lung inflammation, joint pains, thirst, sore throat, scabies, vomiting, ringworm, sore eye, cold, sneezing, fever and the diseases related to brain and heart [18]. Spinach is rich in vitamin $\mathrm{A}, \mathrm{E}, \mathrm{C}$ and $\mathrm{K}$, foliate, iron, magnesium and manganese. It also possesses several biological activities like antimicrobial, antiviral, anticancer, antioxidant and anthelmintic properties. Zingiberofficinale commonly called as ginger is an herbaceous perennial flowering plant belongs to the family of "Zingiberaceae". Ginger is widely used as a spice possesses medicinal value. It is used to treat asthma, nausea, colic, cough, cold, rheumatism, loss of appetite, swelling, heart diseases and dyspepsia [19].

\section{Materials and Methods}

\section{Collection of plant material}

Theplant materials considered for the present are Aloe vera, Spinacia oleracea, Zingiberofficinale,Coriandrum sativum and Allium sativum which were collected from the local market of Visakhapatnam.

\section{Microorganisms used}

The microbial strains considered for the present study are Escherichia coli, Staphylococcus aureus, Enterococcus faecalis,
Streptococcus mutans, Candida albicans, Mycobacterium smegmatis and Klebsiella pneumonia.All the strains were obtained from the National Collection of Industrial Microorganisms (NCIM), Pune, Maharashtra, India.

\section{Preparation of extracts}

Aloe veraleaves, Spinacia oleracealeaf, Zingiberofficinalerhizome, Coriandrum sativumleaves andAllium sativumcloves were washed thoroughly under running tap water and then with distilled water to remove dirt. They were then air-dried under shade, away from sunlight for 4-5 days and made into a fine powder using mortar and pestle. Extracts were prepared using the solvent methanol, ethyl acetate, petroleum ether and chloroform at a concentration of 1:10 ratio. The extraction is carried out with vigorous shaking for $48-72 \mathrm{~h}$ followed by filtration. The extract is then concentrated using Rota evaporator and is further diluted to required concentration using DMSO just before use.

\section{Inoculum preparation}

UTI agar medium is used to culture the strains of Escherichia coli and Enterococcus faecalis. Mannitol Salt agar medium is used for the growth of Staphylococcus aureus. The Streptococcus Selection medium used for Streptococcusmutans and Rose Bengal medium used for culturing Candida albicans strains respectively. The agar slants with respective cultures were prepared and incubated at $37^{\circ} \mathrm{C}$ for $24 \mathrm{~h}$. The colonies of test organisms grown overnight were inoculated into $0.85 \%$ normal saline and the turbidity adjusted to $0.5 \mathrm{McF}$ arland using the standard which is equal to $1.5 \times 10^{8} \mathrm{CFU} / \mathrm{ml}$. It was further diluted to obtain the final inoculum of $5 \times 10^{5} \mathrm{CFU} / \mathrm{ml}$.

\section{Antimicrobial assay using MIC method}

MIC was performed as per Clinical and Laboratory Standards Institute guidelines using extracts against bacterial and fungal pathogens in a 96 well u-bottomed microtitre plates. The plant extracts were serially diluted from the concentration of $500 \mathrm{mg} / \mathrm{ml}$ to $0.02 \mathrm{mg} / \mathrm{ml}$ and then added with the final inoculum of $5 \times 10^{5} \mathrm{CFU} /$ $\mathrm{ml}$. The anti-microbial compound and the final inoculum were in the ratio of 1:1 (v/v). Each test performed in triplicate with positive and negative controls. After the addition of inoculum, plates were sealed with aluminum foil and incubated at $37^{\circ} \mathrm{C}$ for $24 \mathrm{~h}$ in the case of bacterial cultures and for $48 \mathrm{~h}$ at $28^{\circ} \mathrm{C}$ for fungal cultures respectively in an incubator. At the end of incubation period, the wells were added with $20 \mu \mathrm{l}$ of $0.1 \mathrm{mg} / \mathrm{ml}$ resazurin dye and incubated for $30 \mathrm{~min}$ for the color development. Presence of bacterial or fungal growth is indicated by a change in the color of the medium to pink, whereas no color change indicates the absence of growth of the organism and the least concentration where there is no growth is considered as an MIC value of that particular compound against bacterial and fungal strains used. The experiment is carried out in triplicate using the standards streptomycin, fluconazole, cefixime and rifampicin. 


\section{Thin layer chromatography}

Thin layer chromatography (TLC) was performed using $0.2 \mathrm{~mm}$ silica coated aluminum sheets purchased from Merck. The mobile phase of chloroform: methanol in the ratio of 9:1 is used for the separation of bioactive compounds present in the plant extracts. $10 \mu \mathrm{l}$ of each extract was spotted separately on the TLC sheet, allowed for the migration of compounds. After complete elution; the spots were identified and calculated $\mathrm{R}_{\mathrm{f}}$ values for each band.

$$
\mathrm{R}_{\mathrm{f}}=\frac{\text { Distance travelled by solute }}{\text { Distance travelled by solvent }}
$$

\section{Direct TLC bioautography method}

Bioautography is a rapid analytical technique used in the identification of bioactive lead/ scaffolds in complex matrices of plant extracts. In this method of direct TLC Bioautography, the developed TLC plate was sprayed with fungal and bacterial suspensions incubated at $25^{\circ} \mathrm{C}$ for $48 \mathrm{~h}$ under humid conditions. After the incubation period, resazurin dye was sprayed and again incubated at $37^{\circ} \mathrm{C}$ for 3 to $4 \mathrm{~h}$. The antimicrobial activity is indicated by the appearance of clear white zones against a purple background on the TLC plate.

\section{Results and Discussion}

\section{Antimicrobial assay}

The antibacterial and antifungal study is carried out against the strains of Escherichia coli, Staphylococcus aureus, Enterococcus faecalis, Streptococcus mutans, Candida albicans, Mycobacterium smegmatisand Klebsiella pneumoniausing the extracts of Aloe vera, Spinacia oleracea, Zingiberofficinale, Coriandrum sativumandAllium sativum. All the extracts showed antimicrobial activity against the tested pathogenic strains and the results were shown in (Table 1). The petroleum ether and methanolic extracts of Aloe vera and Coriandrum sativumis effective against $M$. smegmatis compared with other strains. The extracts prepared with solvents of chloroform, methanol, petroleum ether and ethyl acetate showed antimicrobial activity at a concentration ranging from $250-31.25 \mathrm{mg} /$ $\mathrm{ml}$ respectively against all the tested strains.Spinacia oleraceaandZingiberofficinalepetroleum ether, chloroform and ethyl acetate extracts showed effective inhibitory activity against the strains of M. smegmatisand K. pneumoniae at a concentration of $31.25 \mathrm{mg} /$ $\mathrm{ml}$, whereas, the MIC value ranged from $250-31.25 \mathrm{mg} / \mathrm{ml}$ against the other strains used in the study.Candida albicans and Klebsiella pneumoniae were inhibited at a concentration of $31.25 \mathrm{mg} / \mathrm{ml}$ with Allium sativum methanol and chloroform extracts.

\begin{tabular}{|c|c|c|c|c|c|}
\hline \multirow{2}{*}{ Plant Species } & \multirow{2}{*}{ Strain Name } & \multicolumn{4}{|c|}{ MIC Values mg/ml } \\
\hline & & Chloroform & Methanol & Petroleum ether & Ethyl acetate \\
\hline \multirow{7}{*}{ Aloe veraleaf } & E.coli & 250 & 250 & 250 & 250 \\
\hline & S.aureus & 250 & 250 & 125 & 250 \\
\hline & E. faecalis & 250 & 250 & 125 & 250 \\
\hline & S. mutans & 250 & 250 & 250 & 250 \\
\hline & C. albicans & 62.5 & 62.5 & 125 & 125 \\
\hline & M. smegmatis & 62.5 & 31.25 & 62.5 & 125 \\
\hline & K. pneumonia & 250 & 125 & 250 & 125 \\
\hline \multirow{7}{*}{ Aloe veragel } & E.coli & 125 & 125 & 250 & 250 \\
\hline & S.aureus & 125 & 250 & 250 & 250 \\
\hline & E. faecalis & 250 & 125 & 125 & 125 \\
\hline & S. mutans & 125 & 250 & 250 & 125 \\
\hline & C. albicans & 62.5 & 125 & 125 & 62.5 \\
\hline & M. smegmatis & 62.5 & 31.25 & 31.25 & 62.5 \\
\hline & K. pneumonia & 31.25 & 62.5 & 125 & 62.5 \\
\hline \multirow{7}{*}{ Spinacia oleracea leaf } & E.coli & 125 & 250 & 250 & 250 \\
\hline & S.aureus & 250 & 250 & 250 & 125 \\
\hline & E. faecalis & 125 & 250 & 250 & 125 \\
\hline & S. mutans & 250 & 250 & 250 & 250 \\
\hline & C. albicans & 125 & 125 & 62.5 & 62.5 \\
\hline & M. smegmatis & 62.5 & 31.25 & 31.25 & 62.5 \\
\hline & К. pпеuтопіа & 125 & 62.5 & 125 & 62.5 \\
\hline
\end{tabular}

\section{Table 1}


Current Trends in Biomedical Engineering \& Biosciences

\begin{tabular}{|c|c|c|c|c|c|}
\hline \multirow{7}{*}{ Zingiberofficinalerhizome } & E.coli & 62.5 & 125 & 125 & 62.5 \\
\hline & S.aureus & 250 & 125 & 250 & 125 \\
\hline & E. faecalis & 125 & 125 & 125 & 250 \\
\hline & S. mutans & 125 & 250 & 125 & 125 \\
\hline & C. albicans & 125 & 62.5 & 250 & 250 \\
\hline & M. smegmatis & 125 & 62.5 & 31.25 & 62.5 \\
\hline & K. pneumonia & 62.5 & 31.25 & 250 & 31.25 \\
\hline \multirow{7}{*}{ Coriandrum sativumleaf } & E.coli & 125 & 250 & 125 & 125 \\
\hline & S.aureus & 250 & 250 & 250 & 125 \\
\hline & E. faecalis & 125 & 250 & 250 & 125 \\
\hline & S. mutans & 250 & 250 & 250 & 250 \\
\hline & C. albicans & 125 & 125 & 62.5 & 62.5 \\
\hline & M. smegmatis & 62.5 & 31.25 & 31.25 & 62.5 \\
\hline & K. pneumonia & 125 & 62.5 & 125 & 62.5 \\
\hline \multirow{7}{*}{ Allium sativumclove } & E.coli & 250 & 250 & 250 & 250 \\
\hline & S.aureus & 125 & 250 & 250 & 250 \\
\hline & E. faecalis & 125 & 125 & 125 & 250 \\
\hline & S. mutans & 250 & 125 & 125 & 250 \\
\hline & C. albicans & 62.5 & 31.25 & 125 & 62.5 \\
\hline & M. smegmatis & 125 & 125 & 62.5 & 125 \\
\hline & K. pneumonia & 31.25 & 62.5 & 250 & 62.5 \\
\hline
\end{tabular}

From the above study, it was observed that all the extracts showed potent antimicrobial activity against all the screened bacterial and fungal strains. The plant extracts effectively inhibited the growth of tested pathogenic strains in the order of Mycobacterium smegmatis $>$ Klebsiella pneumoniae $>$ Candida albicans $>$ Enterococcus faecalis $>$ Staphylococcus aureus $>$ Escherichia coli $>$ Streptococcus mutansand the inhibitory effect of plant extracts was in the order of Spinacia oleracea leaf $>$ Aloe veraleaf $>$ Aloe veragel $>$ Coriandrum sativum leaf $>$ Allium sativum cloves $>$ Zingiberofficinalerhizome. The methanol extracts showed higher antimicrobial activity followed by chloroform, petroleum ether and ethyl acetate. The polarities of solvents play a vital role in the extraction of plant secondary metabolites that influence the antimicrobial potential of extracts [20]. The toxicity of solvent, handling of extracts, total yield and the duration of extraction are some of the important factors need to be considered to increase the extraction efficiency in order to obtain maximum product out of the plant material used [21].

The antimicrobial activity of extracts could be due to the presence of several plant bioactive compounds. The method of preparation and the type of solvent influence the antimicrobial potential of plants and the variations in the activity of tested plant species is due to the difference in the composition of phytochemicals. Antibiotics were most commonly used to kill the microbes and protect patients from infectious diseases, but there is an increased emergence of multi drug resistant strains that leads to treatment failure. Microbes acquire resistance to antibiotics preventing destruction by means of intrinsic mechanism [22]. To control human health problems associated with increasing population day by day, there is a need to discover new antimicrobial drugs for combating the growth of harmful microbes. Drugs with therapeutic properties obtained naturally from the source of medicinal plants are of great importance as these natural plant products are likely to be effective against multi drug resistant strains. Secondary metabolites produced by plants are useful in treating diseases like diabetes, heart diseases, infectious diseases and cancer [23]. It was reported that the garlic has an anti-infective property and antimicrobial activity against a large number of microbes including viruses. Allicin primarily inhibits the synthesis of DNA, RNA and proteins, which is an active ingredient of garlic [24]. The antimicrobial activity of garlic is due to the presence of phenolic compounds and organosulfur compounds [25]. Similar work supporting our results of antimicrobial activity of Aloe vera gel against the strains of E.coli and S.aureuswas also reported [26]. The antimicrobial activity ofAloe verajuice against the strains ofMycobacterium smegmatis, S. aureus, Enterococcus faecalis, M. luteus, B. sphericus, P.aeruginosa, K. pneumoniae, E. coli, S. typhimuriumandcandida albicanswas reported [27]. The inhibitory effect of Aloe vera juice against the strains ofM. smegmatis, K.pneumoniae, E. faecalis, M. luteus, C. albicans andB. sphericuswere also reported [28]. Caffeic acid, chlorogenic acid, ferulic acid, flavanols like quercetin, protocatchunic acid and other polyphenols are present in the leaf extracts of fresh coriander [29]. Due to the presence of polyphenols along with quercitin, coriander is used in food and pharmaceutical industries to avoid the bacterial contamination. The antimicrobial and antioxidant potential of polyphenols pres- 
ent in corianderis effective against the strains ofE.coli, P. aerugino$s a$ responsible for urinary tract infections and gastroenteritis and against $S$. aureus, causative organism of pneumonia, toxic shock syndrome and food poisoning. Ginger rhizome contains gingerol and shagelol active compounds along with several bioactive compounds exhibiting a broad range of antimicrobial activity. The inhibitory effect of the ginger ethanol extract against candida albicans was reported [30]. Recent studies revealed that zingerone showed protective action against $E$. coliresponsible for diarrhea. Study shows that the methanol extracts of ginger effectively inhibited the growth of E. coli and S. aureus similar to our study [31]. The inhibition of bacterial strains $S$. typhimurium, E. coli, P. multocida, M. luteus, L. bulgaricus, S. aureus, K. pneumoniae, P. vulgaris and $S$. epidermis by $S$. oleracea was reported [32]. Alkaloids, tannins, steroids, glycosides and terpenoids are some of the phenolic compounds present in the extracts of $S$. oleracea responsible for the antimicrobial activities.

\section{TLC separation of bioactive compounds}

Thin layer chromatography is performed to identify the number of bioactive compounds present within each extract. The extracts prepared using methanol, ethyl acetate and petroleum ether showed 5-6 distinct bands whereas, chloroform extracts of Coriandrum sativum leaf, Spinach leaf, Aloe veraleaf and Zingiberofficinale rhizome showed 6, 8, 5 and 6 distinct bands respectively. All the extracts used in the study gave impressive results which directly represents the presence of phytochemicals. It was observed that theSpinacia oleracea leaf extract possesses a large number of Phyto-constituents compared to others which could be the reason of higher antimicrobial activity.

The separation of the bio active compounds present within the plant extracts is achieved using the technique of thin layer chromatography, revealed the presence of several phytochemicals with different $\mathrm{R}_{\mathrm{f}}$ values. The suitable mobile phase can be selected based on the $\mathrm{R}_{\mathrm{f}}$ values of each compound. The polarity of the compounds can be detected using the $\mathrm{R}_{\mathrm{f}} \mathrm{values}$. The technique of TLC gives idea for the selection of appropriate solvent system for separation of compounds in pure form for further studies.

\section{Direct TLC bioautography method}

The method of direct TLC bioautography is used to detect the compounds with antimicrobial potential present within the plant extracts. Effective inhibition of the tested plant extracts againstharmful pathogens was in the order of Mycobacterium smegmatis $>$ Klebsiella pneumoniae $>$ Candida albicans $>$ Enterococcus faecalis $>$ Staphylococcus aureus $>$ Escherichia coli $>$ Streptococcus mutans. All the herbal extracts used were found to be most effective against Mycobacterium smegmatisandKlebsiella pneumoniae showing clear white zones against a purple background on the TLC plate indicating the antimicrobial activity.

Plant extracts contain a large number of bioactive compounds and thus the screening of compounds exhibiting the antimicrobial activity is necessary which is made easier with the use of the TLC bioautography method. The zones of inhibition with creamy spots against purple background are visualized after spraying the plates with resazurin dye. This method is considered to be convenient for obtaining the reliable information on the activity of single compounds. Study of herbal extracts suggests the use of herbal preparations for preservation of foods, curing infectious diseases caused by pathogenic microbes and to prevent the microbial deterioration of food products. The isolation and characterization of active compounds with biological activities of these herbal plants could be used to generate a novel drug for future prospects.

\section{Conclusion}

From the above study, it can be concluded that all the plant extracts showed promising antimicrobial activity against harmful pathogenic strains. Extracts exhibiting variations in the antimicrobial activity is due to differences in the composition of bioactive compounds extracted depending upon the polarity of the solvent. Further research is going on in this area to isolate and characterize the bioactive compounds of Aloe vera, Coriandrum sativum, Allium sativum andZingiberofficinale, which may provide a scope of developing more effective drugs for combating infectious diseases.

\section{Acknowledgement}

Research lab of K.V. Chaitanya is funded by the grants from the University grants commission (UGC), Govt. of India, 42-197/2013. Divya is thankful for the UGC research fellowship.

\section{Conflict of Interest}

No conflict of interest declared by authors.

\section{References}

1. Ziegler J (2005) Fayard(eds). L'Empire de la honte, France, Paris.

2. Yala D, Merad AS, Mohamedi D, OuarKorich MN (2001) Classification et mode d'action des antibiotiques. Médecine du Maghreb 91: 5-12.

3. Malleswari D, Mohd Khaja M, Rana K, Bagyanarayana G (2017) Antibacterial and Antifungal Activity of Leaf, Stem and Root Extracts of Costuslgneus. Research Journal of Pharmaceutical. Biological and Chemical Sciences 8: 2314.

4. Ashiq B, Sobia C, Rashida P, Muhammad A, Mirza AM (2017) Chemical composition and antifungal potential of medicinal plants against seedborne mycoflora of eggplant (Solanum melongenaL.).Acta Botanica Croatica 76: 72-79.

5. Adediwura FJ, Ogbole O, Anthony O, Egbebunmi O (2011) Larvicidal effect of the petroleum ether, chloroform fractions and methanol extract of buccholziacoriaceaengle seed. International Journal of Pharmaceutical Sciences and Research 2:1736-1739.

6. Njume C, Afolayan AJ, Clarke AM, Ndip RN (2011) Crude ethanolic extracts of Garcinia kola seeds Heckel prolong the lag phase of Helicobacter pylori: inhibitory and bactericidal potential. Journal of Medicinal Food 14: 822-827.

7. Hayam M, Ibrahim, Ferial M, Salem A (2014) Antibacterial activity of some medicinal plant extracts. International Journal of Biological, Bio molecular. Agricultural Food and Biotechnological Engineering 8: 10. 
8. Bukhari S, Nawaz H, Tariq S, Muneer A (2017) In vitro antimicrobial activity of Aloe vera gel on selected urinary pathogens.Biomedica 33.

9. Sahu PK, Giri DD, Singh R, Pandey P, Gupta S, et al. (2013) Therapeutic and medicinal uses of Aloe vera: a review. Pharmacology \& Pharmacy4: 599.

10. Paul SU, Dutta SO, Chaudhuri TK, Bhattacharjee SO (2014) Antiinflammatory and protective properties of Aloe vera leaf crude gel in carrageen an induced acute inflammatory rat models. International Journal of Pharmacy and Pharmaceutical Sciences 6: 368-371.

11. SangilMonroy M, Serra Majem L, Monroy JM, Andrel-lucchi AO, Sánchez Villegas A, et al.(2014) Effects of intake of milk enriched with aloe veraon patients with gastrointestinal reflux disease. Food and Nutrition Sciences 1: 2014.

12. Tanaka M, Misawa E, Yamauchi K, Abe F, Ishizaki C (2015) Effects of plant sterols derived from Aloe vera gel on human dermal fibroblasts in vitro and on skin condition in Japanese women. Clinical, Cosmetic and Investigational Dermatology 8: 95.

13. Kumar S, Tiku AB, Acemannan A (2014) Polysaccharides of Aloe vera gel protects against radiation induced mortality by modulation of immune suppression. In Proceedings of the international conference on radiation biology: frontiers in radiobiology-immunomodulation. Counter measures and therapeutics: abstract book, souvenir and scientific programme.

14. Bahmani M, Shahinfard N, Fasihzadeh SH, Mirhosseini M, RafieianKopaei M (2016) Aloe vera, An update on its phytomedicinal, pharmaceutical and therapeutic properties. Der Pharmacia Lettre 8.

15. Anita D, Gaurav G, Dinesh K, Ritu M (2014) Polyphenolic composition and antimicrobial potential of methanolic coriander (coriandrum sativum) seed extract. International Journal of Pharmaceutical Sciences and Research, p. 5.

16. Zoubiri S, Baaliouamer A (2012) Essential oil composition of Coriandrum sativumseed cultivated in Algeria as food grains protectant. Food Chemistry 122: 1226-1228.

17. Ponmurugan K, Shyamkumar R (2012) Antibacterial effect of Allium sativumcloves and Zingiberofficinalerhizomes against multiple-drug resistant clinical pathogens. Asian Pacific Journal of Tropical and Biomedicine 2: 597-601.

18. Namrata S, Mukul T, Mehta SC (2017) Phytochemical screening and immune modulatory activity of different extract of Spinacia oleracea leaves. International Journal of Pharmaceutical Sciences and Research 8: 878-882.

19. Foster S (2011) Ginger Zingiberofficinale- Your food is your medicine.

20. Parekh J, Jadeja D, Chanda S (2015) Efficacy of aqueous and methanol extracts of some medicinal plants for potential antibacterial activity. Turk J Bio 29: 203-210.
21. Efe MO, Asefon OA, Stephen AJ (2017) The phytochemical constituents and relative antimicrobial activities against clinical pathogens of different seed extracts of Cola nitida(Vent.), Cola acuminata(Beauvoir) and Garcinia kola(Heckel) grown in South West, Nigeria.Journal of Pharmacognosy and Phytochemistry 6(1): 493-501.

22. McDonnell JJ, Tanaka T, Mitchell MJ, Ohte N (2001) Foreword: hydrology and biogeochemistry of forested catchments. In Hydrological Processes 15: $1673-1674$.

23. Lai HY, Lim YY, Kim KH (2010) Blechnum Orientale Linn -a fern with potential as antioxidant, anticancer and antibacterial agent. BMC Complementary and Alternative Medicine 10: 15.

24. Eja ME, Asikong BE, Abriba C, Arikpo GE, Anwan EE, et al. (2007) A comparative assessment of the antimicrobial effects of garlic (Allium sativum) and antibiotics on diarrheagenic organisms. Southeast Asian J Trop MedPublic Health 38(2): 343-348.

25. Raja RDA, Jeeva S, Prakash JW, Antonisamy JM, Irudayaraj V (2011) Antibacterial activity of selected ethno medicinal plants from South India. Asian Pac J Trop Med 4(5): 375-378.

26. Antonisamy JM, Beaulah N, Laju RS, Anupriya G (2012) Anti-bacterial and antifungal activity of Aloe vera gel extract. International Journal of Biomedical and Advance Research 3(3): 184-187.

27. Alemdar S, Agaoglu S (2009) Investigation of invitroantimicrobial activity of Aloe verajuice. Journal of Animal and Veterinary Advances 8(1): 99-102.

28. Gautam CHVS, Rekha M, Mourya P, Sukanya S, Habeeba U(2017) Evaluation of antibacterial and antifungal activity of Aloe vera gel.Indo American Journal of Pharmaceutical Sciences 4(4): 834-839.

29. Anita D, Gaurav G, Dinesh K, Ritu M (2014) Polyphenolic composition and antimicrobial potential of methanolic coriander (coriandrum sativum) seed extract. International Journal of Pharmaceutical Sciences and Research 5: 2302-2308.

30. Chairgulprasert V, PrasertSongskun S, WichaPorn W (2005) Chemical constituents of the essential oil and antibacterial activity of Zingiberwrayivar. halabala. Songklanakarin. Journal of Science and Technology 27: 813-818.

31. Sunilson JAJ, Suraj R, Rejitha G, Anandarajagopa K (2009) Invitro antibacterial evaluation of Zingiberofficinale, Curcuma longa and Alpinia galangalextracts as natural foods preservatives. American Journal of Food Technology 4(5): 192-200.

32. Nasim FH, Saiqa A, Mazhar I, Tahseen G, Amna Nisar K, et al.(2012) Evaluation of antimicrobial activity of extracts of fresh and spoiled Spinacia oleraceaagainst some mammalian pathogens. African Journal of Microbiology Research 6(29): 5847-5851.

\begin{tabular}{l} 
Your next submission with Juniper Publishers \\
will reach you the below assets \\
- Quality Editorial service \\
- Swift Peer Review \\
- Reprints availability \\
- E-prints Service \\
- Manuscript Podcast for convenient understanding \\
- Global attainment for your research \\
- Manuscript accessibility in different formats \\
( Pdf, E-pub, Full Text, Audio) \\
- Unceasing customer service \\
Track the below URL for one-step submission \\
https://juniperpublishers.com/online-submission.php \\
\hline
\end{tabular}

